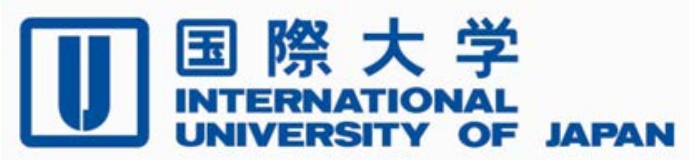

Economics \& Management Series

EMS-2014-06

\title{
Fiscal Stimuli in the Form of Job Creation Subsidies
}

\author{
Chun-Hung Kuo
}

International University of Japan

Hiroaki Miyamoto

The University of Tokyo

May 2014

IUJ Research Institute

International University of Japan

These working papers are preliminary research documents published by the IUJ research institute. To facilitate prompt distribution, they have not been formally reviewed and edited. They are circulated in order to stimulate discussion and critical comment and may be revised. The views and interpretations expressed in these papers are those of the author(s). It is expected that the working papers will be published in some other form. 


\title{
Fiscal Stimuli in the Form of Job Creation Subsidies*
}

\author{
Chun-Hung Kuo \\ Hiroaki Miyamoto ${ }^{\dagger}$ \\ International University of Japan \\ The University of Tokyo
}

May 22, 2014

\begin{abstract}
This paper examines the effects of fiscal stimuli in the form of job creation subsidies in a DSGE model with search frictions in the labor market. We consider two types of job creation subsidies: a subsidy to the cost of posting vacancies and a hiring subsidy. Our model demonstrates that qualitative effects of a vacancy cost subsidy are similar to those of a hiring subsidy. Quantitatively, however, the vacancy cost subsidy is more effective in lowering unemployment than the hiring subsidy. We also compute fiscal multipliers for both traditional increases in government spending and increases in job creation subsidies.
\end{abstract}

JEL Classification: E24; E62; J64

Keywords: Fiscal Policy; Hiring Subsidy; Unemployment; Search and matching

*Part of this research is supported by the Grant-in-Aid for Scientific Research (C) (Kakenhi No. 26380248) and IUJ Research Institute research fund.

${ }^{\dagger}$ Hiroaki Miyamoto (Corresponding author). Mailing address: The University of Tokyo, 7-3-1 Hongo, Bunkyo-ku, Tokyo 113-0033 JAPAN. Tel. +81-3-5841-1411. E-mail: miyamoto@pp.u-tokyo.ac.jp 


\section{Introduction}

Following fiscal stimulus policies employed in the aftermath of the 2007-2008 crisis, a number of studies have analyzed the effectiveness of fiscal stimuli on the labor market (Monacelli et al., 2010; Brückner and Pappa, 2012). These studies mainly focus on the effect of fiscal stimuli in the form of government spending on the labor market. However, a significant portion of stimulus policies undertaken during the Great Recession took the form of labor market subsidies. ${ }^{1}$ Although there are a few studies that analyze the effects of fiscal stimuli in the form of labor market subsidies (Campolmi et al. 2011; Faia et al. 2013), relatively little is known about the effects of them.

The purpose of the paper is to examine the effectiveness of fiscal stimuli in the form of labor market subsidies in a dynamic general equilibrium model. We develop a Real Business Cycle (RBC) model with search frictions in the labor market and study effects of job creation subsidies. We consider two different types of job creation subsidies in our model. One is a subsidy to the cost of posting vacancies, and the other is a hiring subsidy, which is defined as a payment to an employer when a hire is made. A firm receives the vacancy cost subsidy whenever it posts a vacancy, and it does not matter whether the vacant position is eventually filled or not. In contrast, the firm receives the hiring subsidy only when a posted vacancy is filled.

The recent literature, which studies the effectiveness of fiscal stimuli on the labor market in DSGE models, focuses on the role of the subsidy to cost of posting vacancies (Campolmi et al. 2011; Faia et al. 2013). However, the subsidy to the cost of posting vacancies is not a typical job creation subsidy in search and matching models. Traditionally, the job creation subsidy considered in search and matching models is a hiring credit (Mortensen and Pissarides, 1999; Pissarides, 2000; Kitao et al. 2011). Furthermore, in reality, the job creation subsidy takes a form of the hiring subsidy rather than the vacancy cost subsidy. For example, in the U.S. Hiring Incentives to Restore Employment (HIRE) Act, businesses are provided with an additional $\$ 1,000$ credit for every new employee retained for 52 weeks. In this paper, we analyze the effects of these two different job creation subsidies on the labor market. We also compare fiscal multipliers for both an increase in government spending and increases in job creation subsidies.

We find that qualitative effects of the vacancy cost subsidy on the economy are similar to those of the hiring subsidy. An increase in the vacancy cost subsidy or in the hiring subsidy significantly increases vacancies and reduces unemployment. While a higher vacancy subsidy encourages firms to post more vacancies by reducing costs of posting them, a higher hiring subsidy encourages firms to post more vacancies by increasing firms' expected net surplus from newly created jobs. They both foster job creation, lowering unemployment.

\footnotetext{
${ }^{1}$ These subsidy expenditures indeed account for 50 to $80 \%$ of the total fiscal stimuli depending on countries. An important example is the HIRE Act and the American Job Act which focused almost entirely on introducing hiring subsidies.
} 
Quantitatively, however, the vacancy cost subsidy is more effective in creating jobs and in lowering unemployment than the hiring subsidy. The unemployment multiplier for the vacancy cost subsidy is much larger (in the absolute value) than that for the hiring subsidy. This is because all firms posting vacancies benefit from the vacancy cost subsidy, while only firms whose vacancies are filled by workers benefits from the hiring subsidy. We also find that the unemployment multiplier of traditional government spending policy is smaller than those of both job creation subsidy policies. This result is in line with the existing studies, such as Campolmi et al. (2011) and Faia et al. (2013).

Our paper is not the first to analyze the effects of fiscal stimuli in the form of labor market subsidies. Campolmi et al. (2011) develop a New Keynesian Model (NKM) with search frictions and endogenous participation, and study the effects of a vacancy cost subsidy. Faia et al. (2012) also analyze the role of a vacancy cost subsidy in a NKM model with endogenous job separation. While these two paper focus on the vacancy cost subsidy, this paper studies effects of not only the vacancy cost subsidy but also the hiring subsidy. Thus, our paper can be viewed as a complement to Campolmi et al. (2011) and Faia et al. (2013). By using a standard search and matching model, Kitao et al. (2011) quantify the effects of hiring subsidies on the labor market. While they focus on the effects of hiring subsidies on job creation in the search and matching model, this paper analyzes effects of fiscal stimuli in the form of job creation subsidies in the DSGE model.

Our work is also related to a number of recent studies that examine effects of fiscal policies on the labor market. Monacelli et al. (2010) study the effects of fiscal expansion on the U.S. labor market by developing a standard dynamic general equilibrium model with search frictions. Brückner and Pappa (2012) find that for most of OECD countries, an increase in government spending increases both employment and unemployment. They develop a NKM with search frictions and workers' labor participation decisions to explain what they find in the data. None of these papers consider job creation subsidies which our paper focuses on.

The reminder of the paper is organized as follows. Section 2 develops a RBC model with search frictions in the labor market. In the model, we consider two different types of job creation subsidies: a vacancy cost subsidy and a hiring subsidy. In Section 3, we calibrate the model parameters and present the quantitative results of effects of job creation subsidies and government spending shocks on the economy. We also discuss the sensitivity of our results to our choice of parameter values. Section 4 concludes.

\section{The model}

We consider a RBC model with search frictions in the labor market. ${ }^{2}$ An economy consists of a representative household, identical firms, and a government. The household consists of a con-

\footnotetext{
${ }^{2}$ Andolfatto (1996) and Merz (1995) consider a stochastic RBC model with search frictions.
} 
tinuum of workers whose measure is normalized to one. We assume that all agents live forever. The labor market is subject to frictions. Workers and firms cannot meet instantaneously but must go through a time-consuming search process. The household consumes goods, accumulates capital, and provides labor services. Due to frictions in the labor market, some workers are employed and earn wages while others are unemployed and search for jobs. Firms hire workers in the frictional labor market and produce output by using capital and labor, and sell them to households in a competitive market. The government provides unemployment benefits and conducts fiscal stimuli in the form of government spending and job creation subsidies. We consider two different types of job creation subsidies in our model. One is a subsidy to the cost of positing vacancies, which we call a vacancy subsidy. The other is a hiring subsidy which a firm receives when it hires a worker. The government levies a lump sum tax on the household to finance its expenditure. Time is discrete.

Labor market Let $u_{t}$ be the number of unemployed workers and $v_{t}$ be the number of vacancies posted in the economy. The number of matches in period $t$ is determined by the Cobb-Douglas matching function

$$
m_{t}=\gamma_{m} u_{t}^{\xi} v_{t}^{1-\xi}
$$

where the parameter $\gamma_{m}>0$ represents the efficiency of the matching technology and $0<\xi<1$ is the elasticity of the matching function with respect to unemployment. Define $\theta_{t} \equiv v_{t} / u_{t}$ as the labor market tightness. The probability that a firm with a vacant job is matched with a worker is $m_{t} / v_{t}=\gamma_{m} \theta^{-\xi} \equiv q_{t}$. Similarly, the probability that an unemployed worker is matched with a firm with a vacant job is $m_{t} / u_{t}=\gamma \theta_{t}^{1-\xi} \equiv p_{t}$. Note that both firms and workers take $p_{t}$ and $q_{t}$ as given. Following Lubik (2009), we assume that it takes one period for new matches to be productive.

Matches are destroyed at an exogenous rate $s$ which takes place at the end of period $t$. We assume that both existing and newly created matches face the same separation rate. The evolution of employed workers, defined as $e_{t}=1-u_{t}$, is given by

$$
e_{t}=(1-s)\left(e_{t-1}+m_{t-1}\right) \text {. }
$$

Thus, the number of employed workers at period $t$ is given by the number of employed workers at period $t-1$ plus new matches formed in period $t-1$ that were not destroyed.

Firm's Problem We begin by seeing a firm's problem and discuss the roles of two subsidy policies that are designed to foster job creation: the vacancy cost subsidy and the hiring subsidy.

A Firm is free to enter the labor market and posts a vacancy at flow cost $\kappa$ in order to recruit a worker. A vacancy-positing firm receives subsidies $\tau_{t}^{v} \mathcal{K}$ from the government. We call this subsidy a vacancy cost subsidy. In addition to the vacancy cost subsidy, the firm can receive 
a subsidy $\mathcal{H}_{t}$ from the government when it hires a new worker and starts production. This subsidy is called a hiring subsidy. The firm receives the vacancy cost subsidy whenever it posts a vacancy, and it does not matter whether the vacant job is filled or not. In contrast, the firm receives the hiring subsidy only when a posted vacancy is filled.

The value of a firm with a vacant job, $\mathcal{V}_{t}$, is characterized by the following Bellman equation:

$$
\mathcal{V}_{t}=-\left(1-\tau_{t}^{v}\right) \kappa+\beta \mathbb{E}_{t} \frac{\lambda_{t+1}}{\lambda_{t}}\left\{(1-s) q_{t}\left(\mathcal{J}_{n, t+1}+\mathcal{H}_{t+1}\right)+\left[1-q_{t}(1-s)\right] \mathcal{V}_{t+1}\right\},
$$

where $\mathcal{J}_{n}$ is the value of a new match to the firm. A firm incurs cost for posting a vacancy $\kappa$ and receives the vacancy cost subsidy $\tau_{t}^{v} \kappa$. The firm matches with a worker with probability $q_{t}$. If the match is not destroyed, the firm obtains the value of a new match to the firm and the hiring subsidy in the following period; otherwise, it remains as a vacancy.

The value of a new match to a firm satisfies

$$
\mathcal{J}_{n, t}=\max _{k_{n}}\left\{A_{t} f\left(k_{n, t}, h_{n, t}\right)-w_{n, t} h_{n, t}-r_{t} k_{n, t}+\beta \mathbb{E}_{t} \frac{\lambda_{t+1}}{\lambda_{t}}\left[(1-s) \mathcal{J}_{o, t+1}+s \mathcal{V}_{t+1}\right]\right\},
$$

where $\mathcal{J}_{o}$ is the value of an existing match to the firm. Due to the hiring subsidy that a firm receives at the moment of starting production, the value of a new match to the firm is different from that of an existing match to the firm.

In the current period, the firm produces output according to a constant returns to scale production function $y_{h, t}=A_{t} f\left(k_{n, t}, h_{n, t}\right)$, where $A_{t}$ is a technology factor common to all firms, $k_{n, t}$ and $h_{n, t}$ are capital input and hours of work for a newly created match, respectively. The firm pays the labor cost $w_{n, t} h_{n, t}$ and the rental cost of capital $r_{t} k_{n, t}$, where $w_{n, t}$ is the wage rate for a newly hired worker and $r_{t}$ is the real rental rate of capital. In the next period, a match remains with probability $(1-s)$, and the firm obtains the expected value of the job $\mathcal{J}_{o, t+1}$; otherwise, the match is destroyed and becomes vacant. The expected future value of the job is discounted by the stochastic discount factor $\beta \lambda_{t+1} / \lambda_{t}$, where $\beta$ is the household's subjective discount factor and $\lambda_{t}$ is the marginal utility of consumption defined below.

The first-order condition for capital is

$$
A_{t} f\left(k_{n, t}, h_{n, t}\right)=r_{t}
$$

This implies that the optimal capital is chosen to equate the marginal product of capital to the capital rental rate.

Given a wage rate for a worker in an existing match $w_{0, t}$, the value of an existing match to a firm is given by

$$
\mathcal{J}_{o, t}=\max _{k_{0}}\left\{y_{o, t}-w_{o, t} h_{o, t}-r_{t} k_{o, t}+\beta \mathbb{E}_{t} \frac{\lambda_{t+1}}{\lambda_{t}}\left[(1-s) \mathcal{J}_{o, t+1}+s \mathcal{V}_{t+1}\right]\right\}
$$

where $y_{o, t}=A_{t} f\left(k_{0, t}, h_{0, t}\right)$ is the output of a firm with an existing match, $k_{o, t}$ and $h_{o, t}$ are capital input and hours of work for an existing match, respectively. 
The first-order condition for the capital input is

$$
A_{t} f\left(k_{o, t}, h_{o, t}\right)=r_{t}
$$

In equilibrium, all profit opportunities from new jobs are exploited, so that the following free entry condition holds:

$$
\mathcal{V}_{t}=0
$$

Household's problem A representative household consists of a continuum of individuals of mass one. A member of the household is either employed or unemployed. In period $t$, the number of employed workers who worked at existing jobs is denoted by $e_{0, t}$, the number of newly hired employed worker is denoted by $e_{n, t}$, and the number of unemployed workers is denoted by $u_{t}$. Note that $e_{0, t}=(1-s) e_{t-1}$ and $e_{n, t}=(1-s) m_{t-1}$. Following Merz (1995), we assume that family members perfectly insure each other against fluctuations in consumption coming from the unemployment risk.

The household's expected life time utility is given by

$$
\max \mathbb{E}_{0} \sum_{t=0}^{\infty} \beta^{t}\left[\frac{C_{t}^{1-\sigma}}{1-\sigma}-\Phi e_{n, t} \frac{h_{n, t}^{1+\mu}}{1+\mu}-\Phi e_{o, t} \frac{h_{o, t}^{1+\mu}}{1+\mu}\right],
$$

where $\beta \in(0,1)$ is the household's subjective discount factor, $C_{t}$ is consumption of the household, $\Phi>0$ measures the disutility of working, and $\mu$ is the inverse of the Frisch elasticity of labor supply.

Employed household members earn wage, and unemployed household members receive unemployment benefits $z$ from the government. The household receive profits $\Pi_{t}$ from the firms and pays lump sum taxes $T_{t}$ to the government. The household may either consume $C_{t}$ or accumulate capital $K_{t+1}$ through investment $I_{t}$ according to $K_{t+1}=(1-\delta) K_{t}+I_{t}$, where $\delta$ is the depreciation rate.

The budget constraint of the representative household is

$$
C_{t}+K_{t+1}=w_{0, t} n_{o, t} h_{o, t}+w_{n, t} e_{n, t} h_{n, t}+u_{t} z+r_{t} K_{t}+(1-\delta) K_{t}+\Pi_{t}-T_{t} .
$$

The household's problem yields the following first-order conditions

$$
\begin{aligned}
C_{t}^{-\sigma} & =\lambda_{t}, \\
\lambda_{t} & =\beta \mathbb{E}_{t} \lambda_{t+1}\left(1+r_{t+1}-\delta\right),
\end{aligned}
$$

where $\lambda_{t}$ is the Lagrange multiplier on the budget constraint. 
Worker's problem We now turn to the worker's side. Let $\mathcal{W}_{n, t}$ be the value of an employed worker in a newly formed match. It satisfies

$$
\mathcal{W}_{n, t}=w_{n, t} h_{n, t}-\Phi \frac{h_{n, t}^{1+\mu}}{\lambda_{t}(1+\mu)}+\beta \mathbb{E}_{t} \frac{\lambda_{t+1}}{\lambda_{t}}\left[(1-s) \mathcal{W}_{o, t+1}+s \mathcal{U}_{t+1}\right],
$$

where $\mathcal{W}_{o}$ is the value of an employed worker in an existing match and $\mathcal{U}$ is the value of an unemployed worker. The value of an employed worker is composed of the wage income, the disutility from supplying labor $\Phi h_{n, t}^{1+\mu} / \lambda_{t}(1+\mu)$, and the continuation value, which is the value of being employed if the match is not destroyed, or the value of being unemployed if it is destroyed. Similarly, the value of an employed worker in an existing match is

$$
\mathcal{W}_{o, t}=w_{o, t} h_{o, t}-\Phi \frac{h_{o, t}^{1+\mu}}{\lambda_{t}(1+\mu)}+\beta \mathbb{E}_{t} \frac{\lambda_{t+1}}{\lambda_{t}}\left[(1-s) \mathcal{W}_{o, t+1}+s \mathcal{U}_{t+1}\right]
$$

In the current period, an unemployed worker receives the unemployment insurance $z$, and matches with a firm with a vacant job with probability $p_{t}$. If the match is not destroyed, the worker starts production in the following period and obtains the value of being employed; otherwise, she remains unemployed. Thus, the value of an unemployed worker is

$$
\mathcal{U}_{t}=z+\beta \mathbb{E}_{t} \frac{\lambda_{t+1}}{\lambda_{t}}\left\{p_{t}(1-s) \mathcal{W}_{n, t+1}+\left[1-p_{t}(1-s)\right] \mathcal{U}_{t+1}\right\}
$$

Wage bargaining and hours choice Wages and hours worked are determined as the outcome of a bilateral bargaining process between workers and firms. In each period, firms and workers negotiate through Nash bargains. The bargaining problems facing newly hired workers and existing workers are different. For a newly hired worker, she bargains with a firm over the joint surplus of a new match, where the hiring subsidy is taken into account. In contrast, for the existing worker, the joint surplus does not contain the hiring subsidy. ${ }^{3}$

Thus, the initial wage and hours of work are chosen to maximizes the Nash product

$$
\max _{w_{n}, h_{n}}\left(\mathcal{W}_{n, t}-\mathcal{U}_{t}\right)^{\eta}\left(\mathcal{J}_{n, t}-\mathcal{V}_{t}+\mathcal{H}_{t}\right)^{1-\eta}
$$

where $\eta \in(0,1)$ is a worker's bargaining power.

The first-order condition with respect to $w_{n, t}$ yields the wage equation

$$
w_{n, t} h_{n, t}=\eta\left(A_{t} f\left(k_{n, t}, h_{n, t}\right)-r_{t} k_{n, t}+\mathcal{H}_{t}+\theta_{t}\left(1-\tau_{t}^{v}\right) \kappa\right)+(1-\eta)\left(z+\frac{\Phi h_{n, t}^{1+\mu}}{\lambda_{t}(1+\mu)}\right) .
$$

The wage equation is similar to the one in a standard search and matching model. ${ }^{4}$ The wage is a weighted average of the marginal revenue product and the cost of replacing the worker, and

\footnotetext{
${ }^{3}$ This wage determination mechanism is adopted in most of search and matching models. See Pissairdes (2000) and Mortensen and Pissarides (1999).

${ }^{4}$ See, for example, Mortensen and Pissarides (1994) and Pissarides (2000).
} 
of the outside option of the worker, which consists of unemployment benefits and the marginal disutility of supplying labor.

The first order condition with respect to $h_{n, t}$ gives us the hours supply equation

$$
A_{t} f_{h}\left(k_{n, t}, h_{n, t}\right)=\frac{\Phi h_{n, t}^{\mu}}{\lambda_{t}}
$$

which states that hours worked is determined by equalizing the marginal product of hours and the worker's marginal rate of substitution between leisure and consumption.

Once the match is formed, the firm no longer obtains the hiring subsidy. Thus, the wage and hours of work in a continuation match are obtained by

$$
\max _{w_{o}, h_{o}}\left(\mathcal{W}_{o, t}-\mathcal{U}_{t}\right)^{\eta}\left(\mathcal{J}_{o, t}-\mathcal{V}_{t}\right)^{1-\eta}
$$

Taking first-order conditions with respect to $w_{o, t}$ and $h_{o, t}$, we have the following wage and hours supply equations for an employed worker in an existing match:

$$
\begin{aligned}
w_{0, t} h_{0, t} & =\eta\left(A_{t} f\left(k_{0, t}, h_{0, t}\right)-r_{t} k_{0, t}+\theta_{t}\left(1-\tau_{t}^{v}\right) \kappa\right)+(1-\eta)\left[z+\frac{\Phi h_{o, t}^{1+\mu}}{\lambda_{t}(1+\mu)}\right], \\
A_{t} f_{h}\left(k_{0, t}, h_{0, t}\right) & =\frac{\Phi h_{o, t}^{\mu}}{\lambda_{t}} .
\end{aligned}
$$

Government policy and resource constraint The government finances government spending $G_{t}$, the unemployment benefit $u_{t} z$, the vacancy subsidy $\tau_{t}^{v} \kappa v_{t}$, and the hiring subsidy $e_{n, t} \mathcal{H}_{t}$ by imposing the lump-sum tax $T_{t}$ to households. The government budget constraint is thus given by

$$
T_{t}=G_{t}+u_{t} z+\tau_{t}^{v} \kappa v_{t}+e_{n, t} \mathcal{H}_{t}
$$

Government spending $G_{t}$ follows a stochastic process

$$
\log G_{t}=\left(1-\rho_{g}\right) \log G+\rho_{g} \log G_{t-1}+\varepsilon_{g, t}, \quad \varepsilon_{g, t} \sim N\left(0, \sigma_{g}^{2}\right),
$$

where $G$ is the steady-state value of government spending, and $\varepsilon_{g, t}$ is an i.i.d. innovation. Similarly, the two subsidy policies follow stochastic processes

$$
\begin{aligned}
\log \tau_{t}^{v} & =\left(1-\rho_{v}\right) \log \tau^{v}+\rho_{v} \log \tau_{t-1}^{v}+\varepsilon_{v, t}, \quad \varepsilon_{v, t} \sim N\left(0, \sigma_{v}^{2}\right) \\
\log \mathcal{H}_{t} & =\left(1-\rho_{\mathcal{H}}\right) \log \mathcal{H}+\rho_{\mathcal{H}} \log \mathcal{H}_{t-1}+\varepsilon_{\mathcal{H}, t}, \quad \varepsilon_{\mathcal{H}, t} \sim N\left(0, \sigma_{\mathcal{H}}^{2}\right)
\end{aligned}
$$

where $\tau^{v}$ and $\mathcal{H}$ are the steady-state values of the subsides. $\varepsilon_{v, t}$ and $\varepsilon_{\mathcal{H}, t}$ are i.i.d innovations with standard deviations $\sigma_{v}$ and $\sigma_{\mathcal{H}}$, respectively.

Aggregate output and capital are obtained by

$$
Y_{t}=e_{0, t} y_{0, t}+e_{n, t} y_{n, t}
$$


and

$$
K_{t}=e_{o, t} k_{o, t}+e_{n, t} k_{n, t}
$$

respectively.

By combining the household and government budget constraints as well as profits of firms, we have the resource constraint of the economy

$$
C_{t}+I_{t}+G_{t}+\kappa v_{t}=Y_{t}
$$

which implies that aggregate production must equal private and public demand.

\section{Quantitative Analysis}

In this section, we investigate the effects of fiscal policy shocks on the model economy. Shocks on two subsidy policies and government spending are discussed in turn. To do so, we first calibrate the model to match some prominent features observed in US data. We then solve and simulate the model by log-linearizing the equilibrium conditions around the steady state.

\subsection{Calibration}

Since we embed search-and-matching frictions in an otherwise standard real business cycle models, our calibration strategy is largely in line with the existing business cycle literature. We calibrate the model at a monthly frequency and set the subjective discount factor $\beta=0.996$, implying the annual real rate of approximately 4 percent. ${ }^{5}$ The risk aversion coefficient $\sigma$ is set to 2.0. We set $\mu=2$ implying the Frisch elasticity of labor supply of 0.5 , which is consistent with evidence for the U.S. labor market. The labor supply disutility $\Phi$ is pinned down such that in the steady state an average working hours per employee is equal to $1 / 3$. We set the technology parameter $\alpha=0.33$ and the capital depreciation rate $\delta=0.1 / 12$, as are widely adopted in the modern DSGE models. We normalize the technology level to $A=1$ without loss of generality.

We set the exogenous separation rate to $s=0.034$. This choice is in line with the empirical findings of Hall (2005) and Shimer (2005). The former paper finds that the quarterly separation rate is about 8-10 percent in the U.S, and the later paper finds that monthly separation rate of about 3.4 percent. We set the elasticity of matching with respect to unemployment $\xi$ to 0.5 . This choice is within the plausible range of 0.5 to 0.7, reported by Petrongolo and Pissarides (2001).

As a benchmark calibration, we set the worker's bargaining power to $\eta=0.5$ such that the efficiency condition of Hosios (1990) is satisfied. However, it is worth noting that the imposition of this condition is somehow questionable due to lacks of empirical supports. For example, by using Bayesian estimation methods, Lubik (2009) finds that the posterior mean of $\eta$ in the U.S.

\footnotetext{
${ }^{5}$ As Monacelli et at. (2010) argue, the job finding rate in the U.S. is quite high, so unemployed workers on average find a job within a quarter. In order to capture this feature, we choose to calibrate the model at a monthly frequency.
} 
is about 0.03 , which is difficult to reconcile with the empirical values of the matching elasticity with respect to unemployment $\xi$. Thus, we will conduct sensitivity checks on this parameter later on.

We target the steady-state vacancy-unmployment ratio to 0.72 as reported by Pissarides (2009). We also target the job finding rate to 0.45 following Shimer (2005). With these two target values, we solve for the matching efficiency parameter $\gamma_{m}$ and a vacancy cost $\kappa$ from the steady state of the model. See Shimer (2005) for this calibration strategy.

Below we discuss the parameters related to the government policies. We target the unemployment benefit $z$ such that it amounts to 40 percent of the steady state average labor income. ${ }^{6}$ Following Campolmi et al. (2011), we set the steady state government spending to output ratio $G / Y=0.15$ and the steady state vacancy subsidy rate $\tau^{v}=0.01$. We assume that in the steady stage the government spends exact amounts in both subsidies. The steady state hiring subsidy $\mathcal{H}$ can, thus, be pinned down by imposing the condition $\kappa \tau^{v} v=\mathcal{H} e_{n}$. The persistency coefficients $\rho_{j}, j \in\{g, v, \mathcal{H}\}$ are all assumed to take values $0.9^{1 / 3}$. The parameter values are summarized in Table 1.

Selected endogenous variables in the steady state under the calibrated parameters are reported in Table 2. The job-finding rate, the vacancy-unemployment ratio, average hours of work, and the ratio of government spending to output are equal to their target values.

\subsection{Effects of job creation subsidies}

We now study the dynamic responses of the economy to shocks on job creation subsidies. The solid and dashed lines in Figure 1 display the impulse responses of relevant variables to increases in the vacancy cost subsidy and the hiring subsidy, respectively. In particular, we show the effects of raising the vacancy subsidy from $1 \%$ to $2 \%$. The increment of the hiring subsidy is set to be equal to that of the vacancy cost subsidy.

We first examine the effects of an increase in the vacancy cost subsidy. An increase in a vacancy subsidy increases vacancies and employment and reduces unemployment. On the impact, vacancies rise and reach the peak instantly, and then gradually return to its steady-state value. Unemployment falls and reaches its lowest level in the 4th month and then gradually returns to the steady-state value. The response of employment is opposite to unemployment.

These movements in labor market variables can be explained as follows. A higher vacancy cost subsidy encourages firms to post more vacancies by reducing costs of posting them. This increases the job-finding rate, leading to a lower unemployment and a higher employment.

\footnotetext{
${ }^{6}$ This parameter has been the subject of some discussion. For the U.S. labor market, Shimer (2005) sets the parameter value of $z$ by targeting the replacement rate of $40 \%$. Hagedorn and Manovskii (2008) argue that Shimer's value is too low and assume that the flow value of unemployment is much larger and close to productivity level. See Mortensen and Nagypál (2007) for more details.
} 

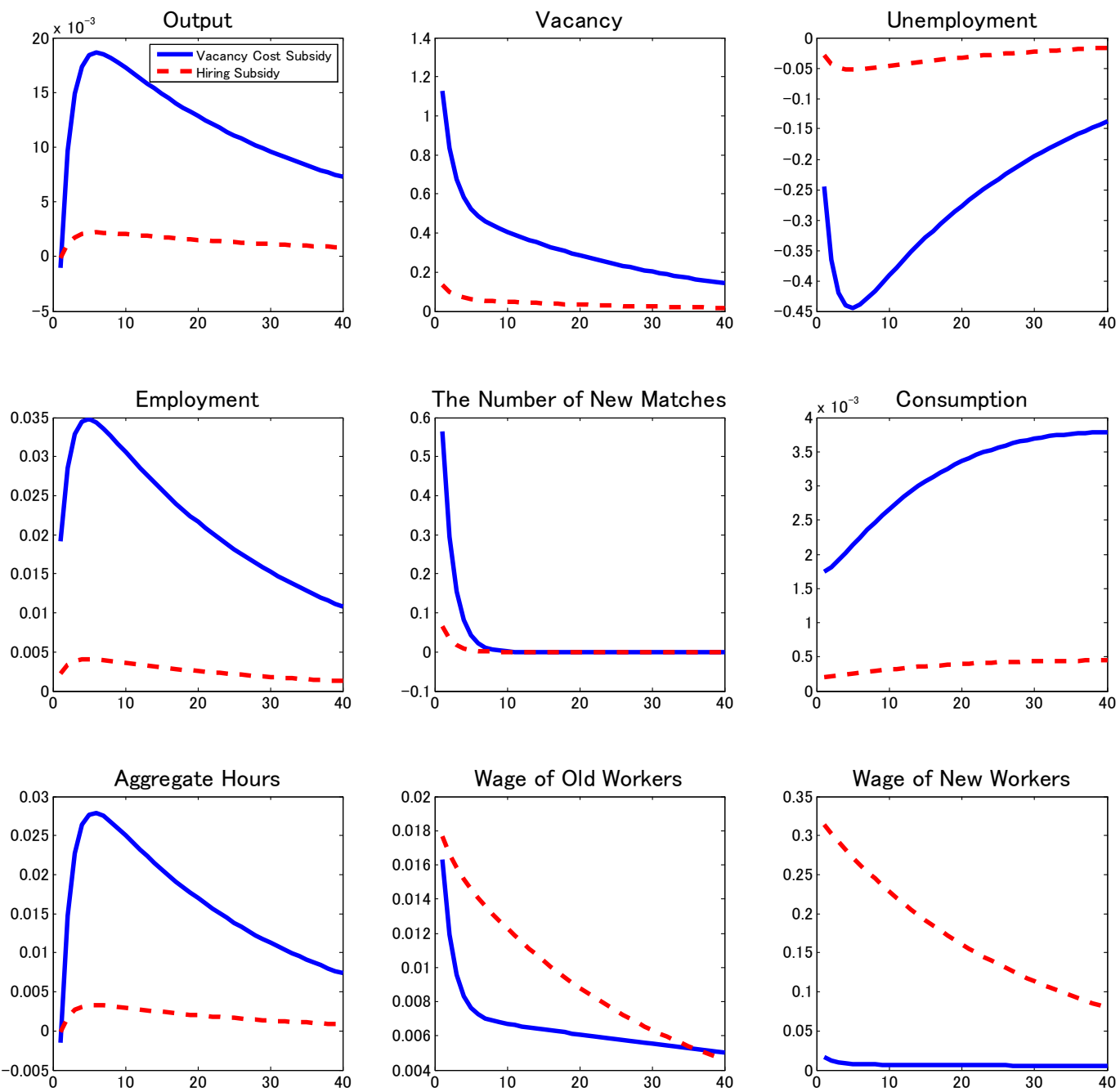

Figure 1: Dynamic responses of the economy to positive shocks on job creation subsidies. Note: The solid lines labeled "Vacancy Cost Subsidy" plot the impulse responses to a positive vacancy cost shock. The dashed lines labeled "Hiring Subsidy" plot the impulse responses to a positive hiring subsidy shock. The horizontal axis represents months after the shock. The vertical axis represents deviations from the steady-state value in percentage points. 
Table 1: Parameter values

\begin{tabular}{llll}
\hline \hline Parameter & Description & Value & Source/Target \\
\hline$\beta$ & Discount factor & 0.996 & Data \\
$\delta$ & Depreciation rate & $0.1 / 12$ & Data \\
$A$ & Aggregate productivity & 1.0 & Normalization \\
$\alpha$ & Parameter in production function & 0.33 & Data \\
$\gamma_{m}$ & Matching efficiency & 0.530 & Job-finding rate \\
$\xi$ & Matching elasticity & 0.5 & Petrongolo and Pissarides (2001) \\
$\mathcal{S}$ & Exogenous separation rate & 0.1 & Shimer (2005) \\
$\sigma$ & Relative risk aversion parameter & 2.0 & See text \\
$\Phi$ & Disutility of labor & 32.41 & Set to target $h=1 / 3$ \\
$\mu$ & Frisch elasticity & 2.0 & See text \\
$z$ & Unemployment benefits & 0.415 & Replacement rate $40 \%$ \\
$\eta$ & Worker's bargaining power & 0.5 & Hosios (1990) condition \\
$\kappa$ & Vacancy cost & 0.418 & $v-u$ ratio \\
$\tau^{v *}$ & Vacancy cost subsidy & 0.01 & Campolmi et al. (2011) \\
$\mathcal{H}$ & Hiring subsidy & 0.007 & See text \\
$\rho_{g}$ & Gov. spending autoregressive parameter & $0.9^{1 / 3}$ & See text \\
$\rho_{v}$ & Vacancy cost subsidy autoregressive parameter & $0.9^{1 / 3}$ & See text \\
$\rho_{\mathcal{H}}$ & Hiring subsidy autoregressive parameter & $0.9^{1 / 3}$ & See text \\
\hline
\end{tabular}

The positive vacancy cost subsidy shock increases hours of work and employment significantly, increasing output. The positive vacancy cost subsidy shock also increases the wage rate, increasing the household's income. Due to this positive wealth effect, consumption also rises.

The qualitative effects of the hiring subsidy on the economy are similar to those of the vacancy cost subsidy. An increase in the hiring subsidy increases vacancies and reduces unemployment. It increases hours of work and the wage rate, leading to a higher consumption. Although both shocks increase vacancies and reduce unemployment, the mechanisms behind them are different. While a higher vacancy cost subsidy encourages firms to post vacancies by reducing the cost of posting them, a higher hiring subsidy encourage by increasing firms' expected net surplus from newly created jobs. Both foster job creation, leading to a lower unemployment and a higher employment.

Quantitatively, however, the effects of the vacancy cost subsidy are different from those of the hiring subsidy. In response to the vacancy subsidy shock, vacancies increase by about $0.011 \%$ and unemployment decreases about $0.004 \%$ at the peak. On the other hand, in response to the hiring subsidy shock, vacancies increase by about $0.001 \%$ from its steady state value and unemployment falls by $0.0005 \%$ at the peak. Thus, the vacancy cost subsidy is more effective 
Table 2: Model solutions

\begin{tabular}{lll}
\hline \hline Variables & Description & Solution \\
\hline$\theta$ & Labor market tightness & 0.72 \\
$u$ & Unemployment & 0.073 \\
$v$ & Vacancy & 0.052 \\
$n$ & Employment & 0.927 \\
$p$ & Job-finding rate & 0.450 \\
- & Average hours worked & 0.333 \\
$w_{n}$ & Wage rate for a newly hired worker & 3.387 \\
$w_{o}$ & Wage rate for an existing worker & 3.373 \\
$C$ & Aggregate consumption & 0.980 \\
$G$ & Government spending & 0.240 \\
$Y$ & Aggregate output & 1.600 \\
$I$ & Aggregate investment & 0.360 \\
\hline
\end{tabular}

in creating jobs and in lowering unemployment than the hiring subsidy. This is because the vacancy cost subsidy affects all firms with vacant jobs, while the hiring subsidy affects only firms with vacant jobs that are filled by workers.

\subsection{Effects of a government spending shock}

Below, we study the dynamic responses of the economy to a positive government spending shock. Results are shown in Figure 2. An increase in government spending increases output and hours of work. A negative wealth effect increases hours of work, leading to higher output that each match produces. Furthermore, as seen below, the increase in government spending raises employment, which further increases the aggregate output. The positive government spending shock crowds out private consumption.

The increase in government spending leads to a significant fall in unemployment and increases in employment and vacancies. On the impact, unemployment falls and reaches its lowest level in the 4th month and then gradually returns to its steady-state value. The pattern of the employment response is opposite to that of unemployment. On the impact, vacancies rise instantly and gradually return to its steady-state value. The pattern of responses of unemployment, employment, and vacancies are in line with what we observe in the data. ${ }^{7}$

These movements in labor market variables can be explained as follows. A positive government spending shock induces a negative wealth effect that raises the value of the match's surplus by reducing the value of non-work activity, in particular by reducing the component

\footnotetext{
${ }^{7}$ See, for example, Monacelli et al. (2010).
} 

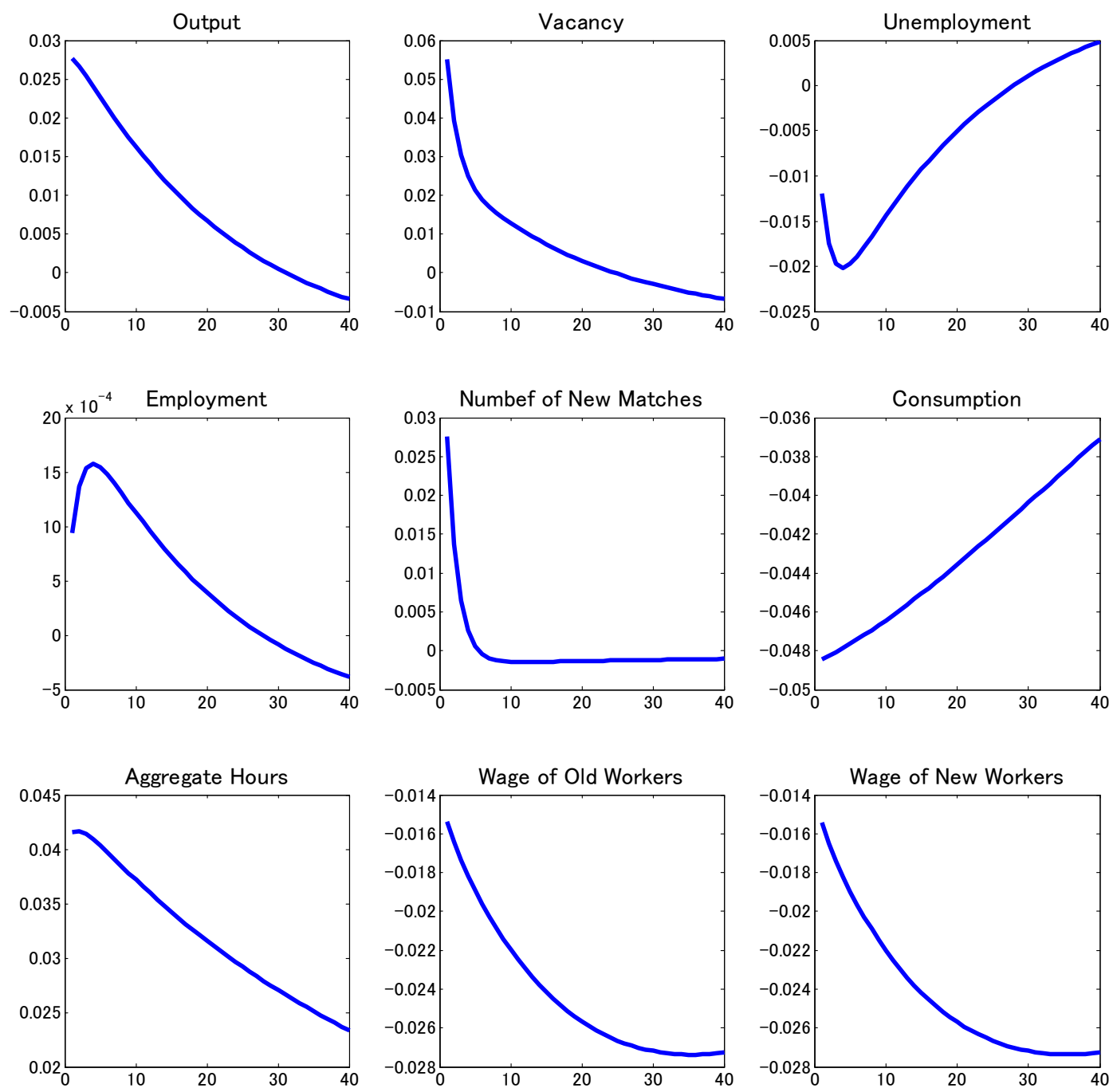

Figure 2: Dynamic responses of the economy to a positive government spending shock. Note: The results are based on a $1 \%$ increase of government spending from its steady state value. The horizontal axis represents months after the shock. The vertical axis represents deviations from the steady-state value in percentage points. 
associated with the disutility from supply hours of work. The higher surplus, shared between the firm and the worker by Nash bargaining, in turn raises job creation. This leads to a higher employment and a lower unemployment.

\subsection{Multipliers}

Recently, a number of studies compute fiscal multipliers for both traditional increases in government spending and increases in job creation subsidies. We now compute output and unemployment multipliers for both increases in government spending and increases in job creation subsidies. Following Faia et al. (2012), we compute the net present value fiscal multipliers:

$$
\operatorname{Multi}_{t, t+j}^{x}=\frac{\sum_{t=1}^{j} \beta^{i-1}\left(x_{t+i}-x\right)}{\sum_{t=1}^{j} \beta^{i-1}\left(\Omega_{t+i}-\Omega\right)},
$$

where $x_{t}=Y_{t}$ for the output multiplier, while $x_{t}=u_{t}$ for the unemployment multipliers. When considering the traditional demand stimulus, the cost is given by $\Omega_{t}=G_{t}$, while considering increases in the vacancy cost subsidy and in the hiring subsidy, the cost are given by $\Omega_{t}=\kappa v_{t} \tau_{t}^{v}$ and $\Omega_{t}=\mathcal{H}_{t} e_{n, t}$, respectively. The variables without time subscript denote the steady state values of them.

Figure 3 shows the results. The unemployment multipliers for the job creation subsidy policies are much larger (in absolute values) than that for the government spending policy. This implies that job creation subsidies are more effect in lowering unemployment than government spending. This result is in line with the existing studies, such as Campolmi et al. (2011) and Faia et al. (2013).

It is important to be careful when we interpret these multipliers. The caution comes from two facts. First, the quality of the model implications is better when a shock to the economy is not far from the steady state, since we log-linearize the equilibrium conditions. Second, the magnitudes for these two policies are quite different. In our benchmark calibration, the government consumes 15 percent of aggregate output in the steady state, while it only subsidies 1 percent for the firms' vacancy posting cost. Therefore, it will be inadequate to interpret that when the government increases the vacancy posting cost subsidy for 1 percent of GDP, the GDP will increase more than 2 percent, since such a policy shock is far from the steady state value of the vacancy cost subsidy.

The unemployment multiplier for the hiring subsidy is smaller than (in the absolute value) that of the vacancy cost subsidy. As mentioned earlier, this is because the vacancy cost subsidy affects all firms with vacant jobs, while the hiring subsidy affects only firms with vacant jobs that are filled by workers.

We now turn to see the output multipliers. At the period in which a shock occurs, the output multiplier for government spending is larger than the output multipliers for the vacancy cost subsidy and the hiring subsidy. However, when we look at multipliers for longer horizons., 

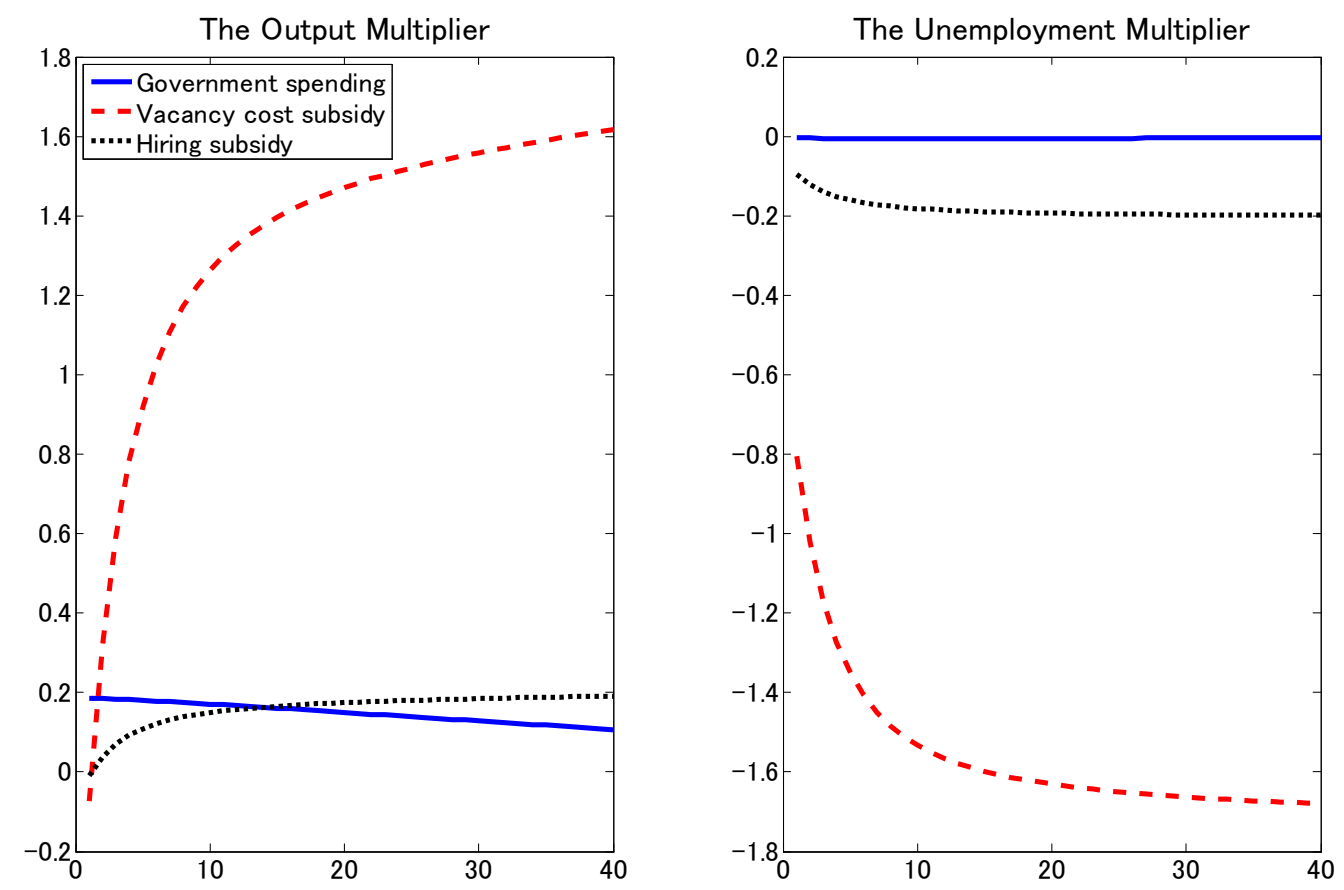

Figure 3: Output and unemployment multipliers Note: Solid lines labeled "Government spending" plot the output and unemployment multipliers for the government spending. The dashed lines labeled "Vacancy cost subsidy" plot the output and unemployment multipliers for the vacancy cost subsidy. The dash-dotted line labeled "Hiring subsidy" plot the output and unemployment multipliers for the hiring subsidy. 
output multipliers for job creation subsidies become larger than the output multiplier for government spending. Furthermore, Figure 3 shows that the multiplier for the vacancy cost subsidy is much larger than that for the hiring subsidy. This result implies that job creation subsidies are more effective in increasing output than government spending. However, it is important to note that we interpret the results with caution.

\subsection{Sensitivity analysis}

We now discuss the sensitivity of the above results to the values of the worker's bargaining power $\eta$, the elasticity of intertemporal substitution $\mu$, and the unemployment benefit $z$. When we change these parameters, we also re-calibrate other parameters in order to maintain our calibration target values.

Changes in these parameter values do not change qualitative effects of vacancy cost subsidy and hiring subsidy shocks on the economy. However, they affect the quantitative effects. Table 3 reports the output and unemployment multipliers for different parameter values. In Table 3 , short-run multipliers reported are the impact multipliers and long-run multipliers are net present multipliers with 12 month horizons.

Table 3: Sensitivity analysis

\begin{tabular}{|c|c|c|c|c|c|c|c|}
\hline & \multirow[t]{2}{*}{ Benchmark } & \multicolumn{2}{|c|}{ Bargaining power } & \multicolumn{2}{|c|}{ Frisch elasticity $(1 / \mu)$} & \multicolumn{2}{|c|}{ Unemployment benefits $(z)$} \\
\hline & & $\eta=0.6$ & $\eta=0.4$ & $\mu=2.5$ & $\mu=1.5$ & $\mathrm{rpr}=0.6$ & $\mathrm{rpr}=0.2$ \\
\hline \multicolumn{8}{|l|}{ Vacancy cost subsidy } \\
\hline \multicolumn{8}{|l|}{ Output multipliers } \\
\hline Short-run & -0.072 & -0.157 & -0.014 & -0.047 & -0.131 & -0.355 & -0.003 \\
\hline Long-run & 1.328 & 1.885 & 0.958 & 1.202 & 1.576 & 3.184 & 0.871 \\
\hline \multicolumn{8}{|l|}{ Unemployment multipliers } \\
\hline Short-run & -0.802 & -1.163 & -0.562 & -0.693 & -1.029 & -2.032 & -0.505 \\
\hline Long-run & -1.561 & -2.261 & -1.094 & -1.351 & -1.998 & -3.896 & -0.986 \\
\hline \multicolumn{8}{|l|}{ Hiring subsidy } \\
\hline \multicolumn{8}{|l|}{ Output multipliers } \\
\hline Short-run & -0.009 & -0.013 & -0.002 & -0.006 & -0.016 & -0.042 & 0.000 \\
\hline Long-run & 0.158 & 0.156 & 0.160 & 0.143 & 0.187 & 0.378 & 0.103 \\
\hline \multicolumn{8}{|l|}{ Unemployment multipliers } \\
\hline Short-run & -0.096 & -0.096 & -0.094 & -0.083 & -0.123 & -0.242 & -0.060 \\
\hline Long-run & -0.186 & -0.187 & -0.183 & -0.160 & -0.237 & -0.462 & -0.117 \\
\hline
\end{tabular}

Note: In the benchmark case, $\eta=0.5, \mu=2.0$, and replacement ratio is 0.4 .

We first examine the effects of changes in the worker's bargaining power. It is important to 
note that the size of vacancy costs in the steady state is relevant when we see the effect of the job creation subsidy. This is because multipliers are computed based on the level of vacancy subsidy costs. If the costs start with a smaller value, multipliers tend to be larger. With a higher value of the worker's bargaining power, the match surplus to a firm becomes smaller, lowering vacancies posted. This leads to a smaller vacancy cost. As a result, output and unemployment multipliers are larger under higher values of the bargaining power. The same argument is applied for the case of a hiring subsidy, as the size of the hiring subsidy is set to be equal to that of the vacancy cost subsidy.

We next consider the effect of changes in the Frisch elasticity. Both output and unemployment multipliers get smaller as $\mu$ increases. In the model, the marginal cost of production equals to the marginal rate of substitution between consumption and leisure. An increase in convexity in the disutility of labor increases the marginal cost of production, lowering marginal profits. This discourages firms from posting vacancies, and makes it harder for workers to find jobs.

At last, we discuss the sensitivity of the results to our choice of the unemployment benefits. In the benchmark case, the value of $z$ is calibrated by targeting the replacement rate (rpr) of $40 \%$. Here, we consider two different values of $z$ that are obtained by targeting the replacement rate of $20 \%$ and $60 \%$. As $z$ increases, output and unemployment multipliers become larger. This finding can be explained by the argument of Hagedorn and Manovskii (2008). They argue that with a higher value of $z$, firms make small profits and more responsive to a productivity shock. Thus, a higher value of $z$ increases the volatility of unemployment in a search and matching model in response to productivity shocks. Our result suggests that this argument is also applied when we analyze the effect of job creation subsidy shocks.

\section{Conclusion}

This paper studies the effectiveness of fiscal stimuli in the form of labor market subsidies. We develop a Real Business Cycle model with search frictions in the labor market, and study the effects of job creation subsidies on the economy. We consider two types of job creation subsidies. One is a subsidy to the cost of posting vacancies and the other is a hiring subsidy. While a firm receives the vacancy cost subsidy whenever it posts a vacancy, the firm receives the hiring subsidy only when a hire is made.

Our model demonstrates that effects of a vacancy cost subsidy are qualitatively similar to those of a hiring subsidy. An increase in the vacancy cost/hiring subsidy increases vacancies and employment and reduces unemployment. Quantitatively, however the vacancy cost subsidy is more effective in lowering unemployment than the hiring subsidy. We also compute fiscal multipliers for both traditional increases in government spending and increases in job creation subsidies. Our model demonstrates that job creation subsidies deliver larger multipliers than government spending does. 
One remaining important issue for future research is the incorporation of endogenous job separation into our model. Our model assumes that while a worker's transition from unemployment to employment is endogenously determined through a matching market, employed workers lose their jobs due to exogenous separation shock. However, recent empirical studies demonstrate that both inflow and outflow of unemployment are important determinants to unemployment dynamics. ${ }^{8}$ Furthermore, as Kitao et al. (2011) show, it is important to take into account a job separation channel when we analyze effects of job creation subsidies. To examine the effects of job creation subsidies in a model with endogenous job separation is left for future research.

\section{References}

[1] Andolfatto, D., 1996. Business cycles and labor market search. American Economic Review $86,112-132$.

[2] Brückner, M., Pappa, E., 2012. Fiscal Expansions, Unemployment, and Labor Participation. International Economic Review 53, 1205-1228.

[3] Campolmi, A., Faia, E., Winkler, R., 2011. Fiscal Calculus and the Labor Market. The B.E. Journal of Macroeconomics. Volume 11, Issue 1.

[4] Den Haan, W., Ramey, G., Watson, J., 2000. Job Destruction and Propagation of Shocks. American Economic Review 90(3), 482-498.

[5] Elsby, M., Michaels, R., Solon, G., 2009. The Ins and Outs of Cyclical Unemployment. American Economic Journal: Macroeconomics 1 (1), 84-110.

[6] Faia, E., Lechthaler, W., Merkl, C., 2013. Fiscal Stimulus and Labor Market Policies in Europe. Journal of Economic Dynamics and Control 37, 483-499.

[7] Fujita, S., Ramey, G., 2009. The Cyclicality of Separation and Job Finding Rates. International Economic Review 50 (2), 415-430.

[8] Hagedorn, M., Manovskii, I., 2008. The cyclical behavior of equilibrium unemployment and vacancies revisited. American Economic Review, 98, 1692-1706.

[9] Hall, R. E., 2005. Employment efficiency and sticky wages: evidence from flows in the labor market, Review of Economics and Statistics, 297, 397-407.

[10] Hosios, A., 1990. On the Efficiency of Matching and Related Models of Search and Unemployment. Review of Economic Studies 57, 279-298.

\footnotetext{
${ }^{8}$ See, for example, Elsby et al. (2009), Fujita and Ramey (2009), and Petrongolo and Pissarides (2008).
} 
[11] Kitao, S., Şahin, A., Song, J., 2011. Hiring Subsidies, Job Creation and Job Destruction. Economics Letters, 113 (3), 248-251.

[12] Merz, M., 1995. Search in the labor market and the real business cycle. Journal of Monetary Economics 36, 269-300.

[13] Monacelli, T., Perotti, R., Trigari, A., 2010. Unemployment Fiscal Multipliers. Journal of Monetary Economics, 57(5), 531-553.

[14] Mortensen, D. T., Pissarides, C. A., 1994. Job creation and job destruction in the theory of unemployment. Review of Economic Studies 61, 397-415.

[15] Mortensen, D.T., Pissarides, C.A., 1999. Job reallocation and employment fluctuations. In: Woodford, M., Taylor, J.B. (Eds.), Handbook of Macroeconomics, vol. 1. Elsevier Science, Amsterdam, pp. 1171-1227.

[16] Mortensen, D. T., Nagypál, E., 2007. More on Unemployment and Vacancy Fluctuations. Review of Economic Dynamics 10, 327-347.

[17] Petrongolo, B., Pissarides, C. A., 2001. Looking into the Black Box: A Survey of the Matching Function. Journal of Economic Literature 39, 390-431.

[18] Petrongolo, B. and Pissarides, C. A., 2008. The ins and outs of European unemployment. American Economic Review 98, 256-62.

[19] Pissarides, C. A., 2000. Equilibrium Unemployment Theory, second ed. MIT Press, Cambridge, MA.

[20] Pissarides, C. A., 2009. The unemployment volatility puzzle: is wage stickiness the answer? Econometrica 77, 1339-1369.

[21] Shimer, R., 2005. The cyclical behavior of equilibrium unemployment and vacancies. American Economic Review 95, 25-49. 